\title{
Polymorphisms of CYP3A5 Affect Serum Levels and Maintenance Doses of Tacrolimus in Myasthenia Gravis Patients
}

Naoki Kawaguchi ${ }^{1,2^{\star}}$, Kaname Nakatani ${ }^{3}$, Akiyuki Uzawa1, Yuko Nemoto ${ }^{1}$, Keiichi Himuro ${ }^{1}$ and Satoshi Kuwabara ${ }^{1}$

${ }^{1}$ Department of Neurology, Graduate School of Medicine, Chiba University, Chiba, Japan

${ }^{2}$ Dowa Institute of Clinical Neuroscience, Chiba, Japan

${ }^{3}$ Department of Laboratory Medicine, Graduate School of Medicine, Mie University, Mie, Japan

\begin{abstract}
Objectives: To evaluate the influences of polymorphisms of cytochrome P450 (CYP) 3A5 (A6986G, CYP3A5*3) on serum levels of tacrolimus and cyclosporine (CyA) in patients with myasthenia gravis (MG).

Methods: This study included 74 MG patients treated with tacrolimus $(n=65)$ or CyA $(n=22)$. Genomic DNA was extracted and amplified with specific primers, and CYP3A5 alleles were confirmed by direct sequencing of PCR products on an automated AB13100 DNA sequencer. We measured blood trough level $\left(\mathrm{C}_{0}\right)$ of tacrolimus and CyA. Clinical disabilities were evaluated with the MG-ADL scale.

Results: For tacrolimus $\mathrm{C}_{0}$, the $C Y P 3 A 5^{*} 3{ }^{*} 3$ genotype was associated with higher levels than the $C Y P 3 A 5^{*} 1{ }^{*} 3$ genotypes $(7.1 \mathrm{ng} / \mathrm{ml}$ versus $2.9 \mathrm{ng} / \mathrm{ml} ; \mathrm{P}<0.0001)$ and $C Y P 3 A^{*} 1 /^{*} 1(7.1 \mathrm{ng} / \mathrm{ml}$ versus $1.3 \mathrm{ng} / \mathrm{ml} ; \mathrm{P}<0.0004)$. The improvement in the mean MG-ADL scores tended to be better in MG patients with the CYP $3 A 5^{*} 3 /{ }^{*} 3$ or $C Y P 3 A 5^{*} 1 /{ }^{*} 3$ than those with CYP $3 A 5^{\star} 1 /{ }^{*}$. For the CyA concentrations, CYP3A5 genotypes did not have significant effects.

Conclusion: In MG patients, CYP3A5 polymorphism significantly affects serum levels of tacrolimus and thereby treatment effects, but not those of CyA. The maintenance dose of tacrolimus should be determined considering CYP3A5 polymorphism.
\end{abstract}

Keywords: Myasthenia gravis; Cytochrome P450; CYP3A; Calcineurin inhibitor; Tacrolimus; Cyclosporine

Abbreviations: CyA: Cyclosporine; MG: Myasthenia Gravis; AChR: Acetyl Choline Receptor

\section{Introduction}

Myasthenia gravis (MG) is an autoimmune disorder of neuromuscular transmission caused primarily by autoantibodies specific to the human nicotinic acetylcholine receptor (AChR). Characteristic symptoms include fatigability and weakness of the striated muscles $[1,2]$. Immunosuppressant therapy is commonly employed to improve MG symptoms and prevent the destruction of the neuromuscular junctions by AChR-antibodies. Currently, MG is treated with several immunomodulating or immunosuppressive agents, including tacrolimus and cyclosporine (CyA) that inhibit calcineurin. Calcineurin inhibitors (CNIs) interfere with T-lymphocyte activation and transcription of inflammatory cytokines such as interleukin-2. A recent study indicates that while low-dose tacrolimus is effective for treating MG [3-6], CNIs have a narrow therapeutic index with variable pharmacokinetics and bioavailability after oral administration [7]. In recent years, the biological activity of the cytochrome P450 (CYP) enzyme system has been shown to play an important role in CNI efficacy $[8,9]$. Specifically, CYP3A is responsible for the phase I metabolism of more than $50 \%$ of drugs [9] including CNIs. As CYP3A5 is expressed in a limited number of individuals and is absent in $73 \%$ of Chinese and $70 \%$ of Caucasians. The expression of CYP $3 A 5$ has recently been correlated with a genetic polymorphism $\left(C Y P 3 A 5^{\star} 3\right)[10,11]$. Moreover, at least one $C Y P 3 A 5^{\star} 1$ allele is required for substantial expression of $C Y P 3 A 5$. Because CYP3A5 may comprise up to $50 \%$ of total CYP3A protein in individuals polymorphically expressing $C Y P 3 A 5$, it may play a major role in variations of CYP3A-mediated drug metabolism. Indeed, dose normalized blood concentrations of tacrolimus have been correlated with CYP3A5 genotypes in kidney, heart, lung, and liver transplanted patients [12-17]. In these studies, tacrolimus concentrations (trough levels) in kidney, heart, and lung transplanted patients after tacrolimus administration were lower in patients who expressed $C Y P 3 A 5^{*} 1{ }^{*} 1$ and $C Y P 3 A 5^{*} 1 /^{*} 3$ alleles than in those who expressed $C Y P 3 A 5^{*} 3{ }^{*} 3$ allele [12-16]. However, the translational link between interindividual variability in CYP3A-mediated drug disposition and clinical improvement of MG patients with polymorphisms in CYP3A5 genes remains to be examined.

The aim of a pharmacogenetics is to optimize drug therapy through characterization of the patients' genotype and to ensure maximum efficacy with minimal adverse effects [18-20]. This illustrates the concept of personalized medicine, in which drugs and drug combinations are optimized for an individual's unique genetic makeup $[21,22]$. The wider use of pharamocogenetic testing is currently viewed as an important tool to improve safety and efficacy [18-21]. This study is the first to show the utility of genotyping in individualizing therapy for $M G$ patients.

\section{Patients and Methods}

\section{Patients}

All MG patients visiting the outpatient clinic of Chiba University Hospital, Chiba, Japan, who were treated with CNIs at least 4 months

*Corresponding author: Naoki Kawaguchi, Dowa Institute of Clinical Neuroscience, 1-2-12 Bentencho, Chuo Ward, Chiba, Chiba Prefecture 260-0045, Japan, Tel: +8143-207-6011; E-mail: kawaguchi@faculty.chiba-u.jp

Received: March 30, 2018; Accepted April 11, 2018; Published April 18, 2018 Citation: Kawaguchi N, Nakatani K, Uzawa A, Nemoto $Y$, Himuro K, et al (2018) Polymorphisms of CYP3A5 Affect Serum Levels and Maintenance Doses of Tacrolimus in Myasthenia Gravis Patients. J Pharmacovigil 6: 258 doi:10.4172/2329-6887.1000258

Copyright: (c) 2018 Kawaguchi N, et al. This is an open-access article distributed under the terms of the Creative Commons Attribution License, which permits unrestricted use, distribution, and reproduction in any medium, provided the original author and source are credited. 
before the start of the study, were eligible for this study. Seventy-four Japanese MG patients receiving either tacrolimus $(n=65)$ or CyA $(\mathrm{n}=22)$ were recruited, and they gave informed consent. Thirteen patients had received treatment with tacrolimus and CyA previously. During routine visits, blood samples were collected for analysis of tacrolimus and CyA concentrations and clinical parameters at 4 months after CNI treatment. Tacrolimus ( $3 \mathrm{mg} /$ day) was administrated orally in a single dose every evening. CyA ( $3 \mathrm{mg} / \mathrm{kg}$ of the body weight) was administrated daily in 2 equal oral doses. All patients treated with CyA used the micro emulsion formulation. Patients with liver dysfunction or severe gastrointestinal disorders that could interfere with their ability to absorb oral medications and those receiving other drugs that may interfere with immunosuppressant drug disposition were excluded. Patients taking medications that are known to interact with calcineurin inhibitors, such as calcium channel blockers (diltiazem, nicardipine, and verapamil), antiepleptics (phenytoin and carbamazepine), antimycotics (fluconazole and ketoconazole), and macrolide antibiotics (erythromycin and clarithromycin) were not eligible for entry into the study.

\section{Clinical studies}

We recorded the daily dose of CNIs and prednisolone (PSL) and measured steady-state blood drug concentrations at trough level $\left(\mathrm{C}_{0}\right)$ 4 months after administration of CNIs. All patients were clinically and biochemically monitored once a month for at least 4 months. Patients were assessed using the MG-activities of daily living (MG-ADL) scale [23]. This semi-quantitative scale has previously been validated in assessing MG [23] and was used in relation to steady-state drug concentrations $\left(\mathrm{C}_{0}\right)$.

\section{Genotyping}

Genomic DNA was isolated from 5 fingernails of MG patients using the QIAamp Blood Kit (Qiagen, Hilden, Germany). Genetic polymorphisms of CYP3A4 (A-392G) and CYP3A5 (A6986G) were identified using specific primers. A fragment containing $A 6986 G$ polymorphism was amplified in 10x PCR buffer containing $2 \mathrm{mM}$ dNTP, $0.1 \mathrm{mM}$ primers (forward: $5^{\prime}$-tacccacgtatgtaccaccc- $3^{\prime}$ and reverse: $5^{\prime}$-gcactgttctgatcacgtcg- $3^{\prime}$ ), and Taq polymerase (Applied Biosystems, Foster City, CA, ABI) and incubated at $95^{\circ} \mathrm{C}$ for $10 \mathrm{~min}$, followed by $40 \mathrm{cycles}$ of $94^{\circ} \mathrm{C}$ for $30 \mathrm{~s}, 58^{\circ} \mathrm{C}$ for $30 \mathrm{~s}, 72^{\circ} \mathrm{C}$ for $30 \mathrm{~s}$, and finally $72^{\circ} \mathrm{C}$ for $7 \mathrm{~min}$. After purification using calf intestine alkaline phosphatase (CIP; Promega, Madison, WI), $1.0 \mu \mathrm{l}$ of purified PCR product was mixed with $2.5 \mu \mathrm{l}$ of SNaPshot Ready Reaction Mix (ABI) and $20 \mathrm{pmol} / \mu \mathrm{l}$ of SNaPshot primer $\left(5^{\prime}\right.$-aagagctcttttgtctttca- $\left.3^{\prime}\right)$. The cycling program consisted of 25 cycles of $96^{\circ} \mathrm{C}$ for $10 \mathrm{~s}, 50^{\circ} \mathrm{C}$ for $5 \mathrm{~s}$, and $60^{\circ} \mathrm{C}$ for $30 \mathrm{~s}$. Post-extension products were purified with CIP, incubated at $37^{\circ} \mathrm{C}$ for $45 \mathrm{~min}$, and then at $75^{\circ} \mathrm{C}$ for $10 \mathrm{~min}$. Final reaction samples $(1.0 \mu \mathrm{l})$ containing extension products were added to $9 \mu \mathrm{L}$ of $\mathrm{Hi}$-Di formamide (Applied Biosystems). The mixture was incubated at $95^{\circ} \mathrm{C}$ for $5 \mathrm{~min}$, incubated on ice for $5 \mathrm{~min}$, and then analyzed by electrophoresis in the ABI Prism 3730 DNA analyzer. Results were analyzed using GeneScan Analysis 3.1 (Applied Biosystems). Since previous reports suggest that $C Y P 3 A 5^{\star} 3$ is the major defective allele and that other functional exonic single-nucleotide polymorphisms (SNPs) are rare in Japanese subjects [10], we detected this allele by identifying CYP3A5 A6986G polymorphism. Patients were divided into 2 groups according to CYP $3 A 5$ genotype as follows: $C Y P 3 A 5^{*} 1{ }^{*} 1$ or $C Y P 3 A 5^{\star} 1 /{ }^{*} 3$ (expressers) and CYP $3 A 5^{*} 3 /{ }^{*} 3$ (non-expressers).

\section{Ethics}

The study was performed in accordance with the Declaration of
Helsinki and its amendments. The protocol was approved by the Ethics Committee of the Chiba University and written informed consent was obtained from all subjects.

\section{Results}

Clinical characteristics of the study population $(n=74)$ are shown in Table 1 . The majority of patients were homozygous for $C Y P 3 A 5^{\star} 3$ variant allele $(\mathrm{n}=44 ; 59.5 \%)$ and were expected to lack CYP3A5 activity. On the other hand, 22 patients $(29.7 \%)$ carried $1 C Y P 3 A 5^{*} 1 /{ }^{*} 3$ allele and 8 patients $(10.8 \%)$ carried $C Y P 3 A 5^{*} 1{ }^{*} 1$ allele. The estimated allele frequencies of $C Y P 3 A 5^{\star} 1$ and $C Y P 3 A 5^{\star} 3$ alleles were $25.7 \%$ and $74.3 \%$, respectively. There were no CYP3A4 mutations among the patients in this study. Among $74 \mathrm{MG}$ patients assessed for CYP3A5 genotype, 65 were treated with tacrolimus and 22 with CyA. Thirteen patients received treatment with tacrolimus and CyA previously. Among patients treated with tacrolimus, CYP3A5 wild-type genotype $\left({ }^{*} 1 /{ }^{*} 1\right)$ was observed in 7 patients $(10.8 \%)$, whereas 20 patients $(30.8 \%)$ were heterozygous and $38(58.4 \%)$ homozygous for CYP3A $5^{*} 3$ allele. A significant difference in tacrolimus $\mathrm{C}_{0}$ and improvement of clinical symptoms was found between the 2 groups at 4 months. Figure 1 shows the differences in trough blood concentrations $\left(\mathrm{C}_{0}\right)$ of tacrolimus between CYP3A5 genotypes 4 months after tacrolimus treatment. The mean tacrolimus $\mathrm{C}_{0}$ for MG patients $(\mathrm{n}=38)$ carrying $C Y P 3 A 5^{*} 3 /{ }^{*} 3$ allele was significantly higher than those $(\mathrm{n}=20)$ carrying $C Y P 3 A 5^{*} 1{ }^{*} 3$ allele $(7.05 \mathrm{ng} / \mathrm{mL}$ versus $2.87 \mathrm{ng} / \mathrm{mL}, p=0.0005$, Mann-Whitney's $U$ test) and those with $C Y P 3 A^{\star} 1{ }^{\star} 1(\mathrm{n}=7 ; 7.05 \mathrm{ng} / \mathrm{mL}$ versus $1.30 \mathrm{ng} / \mathrm{mL}$, $p=0.014)$. In contrast, CYP3A5 polymorphisms did not affect blood CyA concentrations at $\mathrm{C}_{0}$.

The improvements of mean MG-ADL scores (from baseline to 4 months) after tacrolimus administration in $\mathrm{MG}$ patients carrying either CYP3A5*3/*3 (5.4 to 3.4 ) or $C Y P 3 A 5^{\star} 1{ }^{*} 3$ (6.2 to 4.3 ) alleles tended to be better than for those with $C Y P 3 A 5^{*} 1 /{ }^{*} 1$ allele (4.0 to 3.7) in Figure 2. The average dose of PSL (alternate days) for MG patients carrying either $C Y P 3 A 5^{*} 3{ }^{*} 3$ ( $32.1 \mathrm{mg}$ to $25.2 \mathrm{mg} ; p=0.008$, Wilcoxon signedrank test) or $C Y P 3 A 5^{\star} 1 /{ }^{*} 3(24.6 \mathrm{mg}$ to $15.6 \mathrm{mg} ; p=0.010)$ alleles was significantly reduced at 4 months, but not for $C Y P 3 A 5^{\star} 1{ }^{*} 1$ carriers $(8.8 \mathrm{mg}$ to $8.3 \mathrm{mg})$. Side effects of tacrolimus, including deterioration of diabetes mellitus, elevation of serum creatinine, hyperlipidemia, and finger tremors, were noted in 5 of $38 \mathrm{MG}$ patients carrying CYP $3 A 5^{\star} 3{ }^{*} 3(7.6 \%), 3$ of 20 patients carrying CYP $3 A 5^{\star} 1{ }^{*} 3(15.0 \%)$ and 2 of 7 patients carrying $C Y P 3 A 5^{*} 1 /{ }^{*} 1(28.6 \%)$ polymorphisms. The side effects of tacrolimus in patients carrying CYP $3 A 5^{\star} 1{ }^{\star} 1$ allele tended to be more prevalent than in patients carrying other alleles. On the other hand, there were no significant differences between

\begin{tabular}{|c|c|}
\hline \multicolumn{2}{|c|}{ Clinical characteristics } \\
\hline Male: Female & $28: 46$ \\
\hline Mean age at onset & $46.0(4-80)$ \\
\hline Disease duration (years) & $9.1(0-44)$ \\
\hline Thymus histology & - \\
\hline Atrophic thymus & 17 \\
\hline Hyperplasia & 4 \\
\hline Thymoma & 17 \\
\hline Invasive thymoma & 13 \\
\hline Others & 21 \\
\hline Medications & - \\
\hline Tacrolimus & $65 / 74$ \\
\hline Cyclosporine & $22 / 74$ \\
\hline
\end{tabular}

Table 1: Clinical characteristics of myasthenia gravis (MG) patients. 


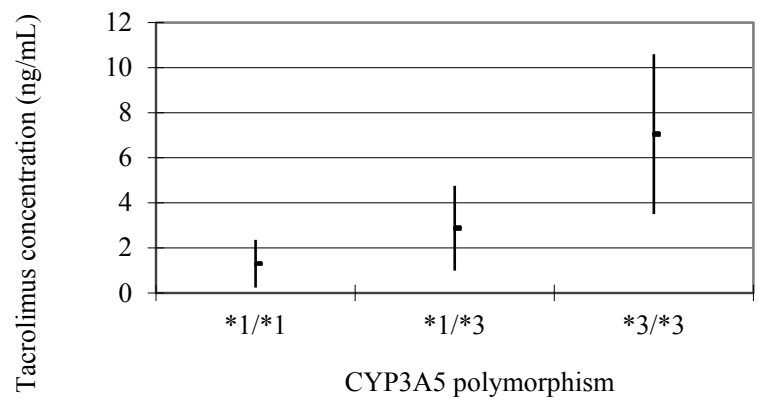

B

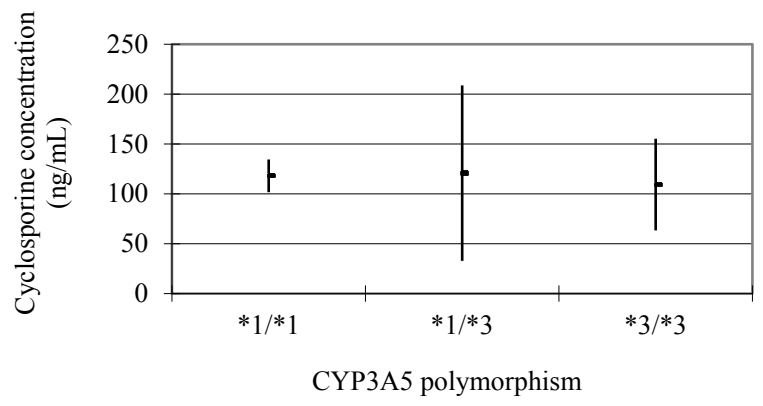

Figure 1: Differences in the trough blood concentrations $\left(C_{0}\right)$ of tacrolimus between groups with CYP3A5 polymorphisms 4 months after treatment The mean tacrolimus $C_{0}$ for $M G$ patients carrying $C Y P 3 A 5^{*} 3{ }^{*} 3$ allele was significantly higher than that for patients carrying CYP $3 A 5^{*} 1 /{ }^{*} 3$ allele $(7.05 \mathrm{ng} /$ $\mathrm{mL}$ versus $2.87 \mathrm{ng} / \mathrm{mL}, p=0.0005)$ or $C Y P 3 A^{*} 1 /{ }^{*} 1$ allele $(7.05 \mathrm{ng} / \mathrm{mL}$ versus $1.30 \mathrm{ng} / \mathrm{mL}, p=0.014)$. In contrast, CYP3A5 genotype did not affect CyA concentration in the blood at $\mathrm{C}_{0}$.

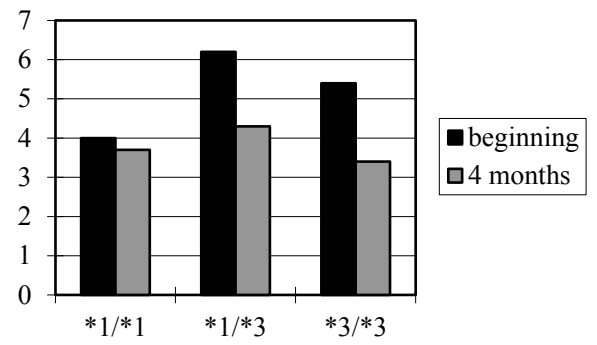

Figure 2: The improvements of mean MG-ADL scores (from baseline to 4 months) after tacrolimus administration in MG patients carrying eithe CYP $3 A 5^{*} 3{ }^{*} 3$ (5.4 to 3.4 ) or CYP $3 A 5^{*} 1{ }^{*} 3(6.2$ to 4.3$)$ alleles tended to be better than for those with $C Y P 3 A 5^{*} 1 /{ }^{*} 1$ allele (4.0 to 3.7$)$.

CYP $3 A 5^{*} 1$ and $C Y P 3 A 5^{*} 3 /{ }^{*}$ allele carriers in effective CyA dose $(\mathrm{mg} /$ $\mathrm{kg})$ or $\mathrm{CyA} \mathrm{C}_{0}(\mathrm{ng} / \mathrm{mL})$ at 4 months.

\section{Discussion}

The calcineurin inhibitors tacrolimus and CyA are new immunosuppressive therapies for MG patients. However, their bioavailability when administered orally is variable. Tacrolimus is metabolized by CYP3A enzymes to form active and inactive metabolites [24-27]. Among the CYP3A subfamily, CYP3A4 and CYP3A5 are the most abundant and important. Hence single nucleotide polymorphisms in $C Y P 3 A 5^{\star} 1 /{ }^{*} 3$ correlate with $C Y P 3 A 5$ expression and function [10]. In vitro, CYP3A5 enzyme is twice as effective at clearing tacrolimus as CYP3A4 enzyme [28] and transplant recipients carrying $C Y P 3 A 5^{\star} 1$ allele(s) have higher clearance, lower concentrations, and delayed time to therapeutic concentration [29-35].

In this study, we examined whether CYP3A5 SNPs contribute to the total metabolic clearance of tacrolimus and CyA. We observed a clear association between $C Y P 3 A 5^{*} 1 /{ }^{*}$ genotype and a lower tacrolimus concentration compared with $C Y P 3 A 5^{*} 3 /{ }^{*} 3 \mathrm{MG}$ patients at 4 months after administration. This observation is in agreement with data showing that $C Y P 3 A 5^{\star} 3$ allele results in the loss of hepatic CYP3A5 activity $[10,11]$, and indicates that patients with $C Y P 3 A 5^{\star} 1{ }^{\star} 3$ genotype require more tacrolimus to achieve the same target blood concentrations than patients with $C Y P 3 A 5{ }^{*} 3 /{ }^{*} 3$ genotype. The frequency of CYP3A5 polymorphisms is significantly variable between ethnic groups. For example, African-Americans have a $27 \%$ to $55 \%$ frequency of $C Y P 3 A 5^{\star} 3$ allele compared with $85 \%$ to $95 \%$ among Caucasian subjects $[10,11]$. CYP $3 A 5^{\star} 3$ allele appears to be fairly common with an estimated allele frequency of $73 \%$ in the Chinese population [11]. In our 74 Japanese MG patients, the estimated allele frequency of $C Y P 3 A 5^{\star} 3$ allele $(74.3 \%)$ is similar to that reported in the Chinese population. Thus, genotyping of MG patients for CYP3A5 variants could be used to predict dose requirements and to avoid the adverse effects of overdosing. Moreover, identification of CYP3A5 variants among patients with other autoimmune disorders and organ transplants might be useful to predict CNI dose requirements.

\section{Conclusion}

In conclusion, we found a significant association between CYP3A5 polymorphism and tacrolimus $\mathrm{C} 0$ and clinical efficacy in $\mathrm{MG}$ patients. Patients carrying $C Y P 3 A 5^{\star} 1$ allele required significantly more tacrolimus to reach target concentrations compared with $C Y P 3 A 5^{*} 3$ homozygotes, leading to poorer clinical outcomes. Thus, they may have a higher probability of under immunosuppression and poor clinical improvement. This information might be used to prospectively individualize immunosuppressive therapy.

\section{References}

1. Drachman DB (1994) Myasthenia gravis. N Engl J Med 330: 1797-1810.

2. Schluep M, Willcox N, Vincent A, Dhoot GK, Newsom-Davis J (1987) Acetylcholine receptors in human thymic myoid cells in situ: An immunohistological study. Ann Neurol 22: 212-222.

3. Konishi T, Yoshiyama Y, Takamori M, Yagi K, Mukai E, et al. (2003) Clinical study of FK506 in patients with myasthenia gravis. Muscle Nerve 28: 570-574.

4. Utsugisawa K, Nagane Y, Yonezawa H, Obara D, Kondoh R, et al. (2003) Effects of FK506 on myasthenia gravis patients with high interleukin-2 productivity in peripheral blood mononuclear cells. Muscle Nerve 27: 245-248.

5. Kawaguchi N, Yoshiyama Y, Nemoto Y, Munakata S, Fukutake T, et al. (2004) Low-dose tacrolimus treatment in thymectomised and steroid-dependent myasthenia gravis. Curr Med Res Opin 20: 1269-1273.

6. Takamori M, Motomura M, Kawaguchi N (2004) Anti-ryanodine receptor antibodies and FK506 in myasthenia gravis. Neurology 62:1894-1896.

7. Yasuhara M, Hashida T, Toraguchi M, Hashimoto Y, Kimura M, et al. (1995) Pharmacokinetics and pharmacodynamics of FK506 in pediatric patients receiving living-related donor liver transplantations. Transplant Proc 27: 1108-1110.

8. Hall SD, Thummel KE, Watkins PB, Lown KS, Benet LZ, et al. (1999) Molecula and physical mechanisms of first-pass extraction. Drug Metab Dispos 27: 161-166.

9. Zhang $Y$, Benet $L Z$ (2001) The gut as a barrier to drug absorption: Combined role of cytochrome P450 3A and P-glycoprotein. Clin Pharmacokinet 40: 159-168. 
Citation: Kawaguchi N, Nakatani K, Uzawa A, Nemoto Y, Himuro K, et al. (2018) Polymorphisms of CYP3A5 Affect Serum Levels and Maintenance Doses of Tacrolimus in Myasthenia Gravis Patients. J Pharmacovigil 6: 258. doi:10.4172/2329-6887.1000258

10. Kuehl P, Zhang J, Lin Y, Lamba J, Assem M, et al. (2001) Sequence diversity in CYP3A promoters and characterization of the genetic basis of polymorphic CYP3A5 expression. Nat Genet 27: 383-391.

11. Hustert E, Haberl M, Burk O, Wolbold R, He YQ, et al. (2001) The genetic determinants of the CYP3A5 polymorphism. Pharmacogenetics 11: 773-779.

12. Thervet E, Anglicheau D, King B, Schlageter MH, Cassinat B, et al. (2003) Impact of cytochrome P450 3A5 genetic polymorphism on tacrolimus doses and concentration-to-dose ratio in renal transplant recipients. Transplantation 76: 1233-1235.

13. Tsuchiya N, Satoh S, Tada H, Li Z, Ohyama C, et al. (2004) Influence of CYP3A5 and MDR1 (ABCB1) polymorphisms on the pharmacokinetics of tacrolimus in renal transplant recipients. Transplantation 78: 1182-1187.

14. Op den Buijsch RA, Christiaans MH, Stolk LM, De Vries JE, Cheung CY, et al. (2007) Tacrolimus pharmacokinetics: Influence of adenosine triphosphatebinding cassette B1 (ABCB1) and cytochrome (CYP) 3A polymorphisms. Fundam Clin Pharmacol 21: 427-435.

15. Zheng HX, Webber S, Zeevi A, Schuetz E, Zhang J, et al. (2003) Tacrolimus dosing in pediatric heart transplant patients is related to CYP3A5 and MDR1 gene polymorphisms. Am J Transplant 3: 477-483.

16. Zheng HX, Zeevi A, Schuetz E, Lamba J, McCurry K, et al. (2004) Tacrolimus dosing in adult lung transplant patients is related to cytochrome P4503A5 gene polymorphism. J Clin Pharmacol 44: 135-140.

17. Goto M, Masuda S, Kiuchi T, Ogura Y, Oike F, et al. (2004) CYP3A5*1-carrying graft liver reduces the concentration/oral dose ratio of tacrolimus in recipients of living-donor liver transplantation. Pharmacogenetics 14: 471-478.

18. Shastry BS (2005) Genetic diversity and new therapeutic concepts. J Hum Genet 50: 321-328.

19. Szekeres T, Haushofer A (2005) Clinical pharamacogenetics of immunosuppressive drugs in organ tranplantaion. Pharamacogenomics 6 : 163-168.

20. Ng FL, Holt DW, MacPhee IA (2007) Pharamacogetics as a tool for optimizing drug therapy in solid-organ transplantation. Expert Opin Pharamacother 8: 2045-2058.

21. Hesselinl DA, Van Gelder T, van Schaik RH (2005) The pharmacogenetics of calcineurin inhibitors: One step closer toward individualized immunesuppression? Pharamacogenomics 6: 323-337.

22. Burckart GJ, Liu XI (2006) Pharamacogenetics in transplant patients: Can it predict pharmacokinetics and pharmacodynamics? Ther Drug Monit 28: 23-30.
23. Wolfe GI, Herbelin L, Nations SP, Foster B, Bryan WW, et al. (1999) Myasthenia gravis activities of daily living profile. Neurology 52: 1487-1489.

24. Shiraga T, Matsuda H, Nagase K, Iwasaki K, Noda K, et al. (1994) Metabolism of FK506, a potent immunosuppressive agent, by cytochrome P450 3A enzymes in rat, dog and human liver microsomes. Biochem Pharmacol 47: 727-735.

25. Mancinelli LM, Frassetto L, Floren LC, Dressler D, Carrier S, et al. (2001) The pharmacokinetics and metabolic disposition of tacrolimus: A comparison across ethnic groups. Clin Pharmacol Ther 69: 24-31.

26. Sattler M, Guengerich FP, Yun CH, Christians U, Sewing KF (1992) Cytochrome P-450 3A enzymes are responsible for biotransformation of FK506 and rapamycin in man and rat. Drug Metab Dispos 20: 753-761.

27. Lecointre K, Furlan V, Taburet AM (2002) In vitro effects of tacrolimus on human cytochrome P450. Fundam Clin Pharmacol 16: 455-460.

28. Dai Y, Hebert MF, Isoherranen N (2006) Effect of CYP3A5 polymorphism on tacrolimus metabolic clearance in vitro. Drug Metab Dispos 34:836-847.

29. Jun KR, Lee W, Jang MS, Chun S, Song GW, et al. (2009) Tacrolimus concentrations in relation to CYP3A and ABCB1 polymorphisms among solid organ transplant recipients in Korea. Transplantation 87: 1225-1231.

30. Macphee IA, Fredericks S, Mohamed M (2005) Tacrolimus pharmacogenetics: The CYP $3 A 5^{*} 1$ allele predicts low dose-normalized tacrolimus blood concentrations in whites and South Asians. Transplantation 79: 499-502.

31. Renders L, Frisman M, Ufer M, Mosyagin I, Haenisch S, et al. (2007) CYP3A5 genotype markedly influences the pharmacokinetics of tacrolimus and sirolimus in kidney transplant recipients. Clin Pharmacol Ther 81: 228-234.

32. Haufroid V, Wallemacq P, VanKerckhove V, Elens L, De Meyer M, et al. (2006) CYP3A5 and ABCB1 polymorphisms and tacrolimus pharmacokinetics in renal transplant candidates: Guidelines from an experimental study. Am J Transplant 6: $2706-2713$

33. Tsuchiya N, Satoh S, Tada H, Li Z, Ohyama C, et al. (2004) Influence of CYP3A5 and MDR1 (ABCB1) polymorphisms on the pharmacokinetics of tacrolimus in renal transplant recipients. Transplantation 78: 1182-1187.

34. Kuypers DR, De Jonge H, Naesens M, Lerut E, Verbeke K, et al. (2007) CYP3A5 and CYP3A4 but not MDR1 single-nucleotide polymorphisms determine longterm tacrolimus disposition and drug-related nephrotoxicity in renal recipients. Clin Pharmacol Ther 82:711-725.

35. Roy JN, Barama A, Poirier C, Vinet B, Roger M (2006) Cyp3A4, Cyp3A5, and MDR-1 genetic influences on tacrolimus pharmacokinetics in renal transplan recipients. Pharmacogenet Genomics 16: 659-665. 